\title{
Concentration After the Nth Dose by Body Mass Index
}

National Cancer Institute

\section{Source}

National Cancer Institute. Concentration After the Nth Dose by Body Mass Index. NCI

Thesaurus. Code C92379.

The concentration at the Nth dose divided by the body mass index. 